\title{
Relato de infecção natural de morcegos por flagelados tripanosomatideos em diferentes municípios do Estado do Rio de Janeiro
}

\author{
Report on natural infection of bats by trypanosomatid flagellates \\ in different municipalities in the State of Rio de Janeiro
}

\author{
Juliana Helena da Silva Barros' ${ }^{1}$ Phyllis Catharina Romijn², Cibele Baptista', \\ Andressa G. de Souza Pinto ${ }^{1}$ e Maria de Fátima Madeira ${ }^{1}$
}

\begin{abstract}
RESUMO
Este trabalho objetivou avaliar a infecção natural de morcegos por tripanosomatídeos. Foram examinados, por hemocultura, 86 exemplares de diferentes gêneros, sendo 22 (25,58\%) amostras isoladas de Desmodus rotundus e Lonchorhina aurita. Os resultados obtidos contribuem para 0 conhecimento da ocorrência de tripanosomatídeos em morcegos no Estado do Rio de Janeiro.
\end{abstract}

Palavras-chaves: Chiroptera. Hemocultura. Trypanosomatidae. Brasil.

\section{ABSTRACT}

This study aimed to evaluate natural infection of bats by trypanosomatids. Using blood culturing, 86 specimens from different genera were examined, and 22 samples (25.58\%) of Desmodus rotundus and Lonchorbina aurita were isolated. These results contribute towards knowledge of the occurrence of trypanosomatids in bats in the State of Rio de Janeiro.

Key-words: Chiroptera. Blood culture. Trypanosomatidae. Brazil.

Os morcegos são mamíferos que possuem hábitos alimentícios diversificados, importantes no equilíbrio ambiental, e na manutenção da diversidade biológica de espécies vegetais, apresentando espécies atuantes e na transmissão de doenças para seres humanos e animais ${ }^{6}$. Das inúmeras espécies de morcegos descritas, apenas três são hematófagas, Desmodus rotundus, Diphylla ecaudata e Diaemus youngii, de ocorrência exclusiva no continente americano. Entre essas, Desmodus rotundus, por ser o único que se alimenta de sangue de mamíferos, constitui maior interesse nas questões de saúde pública, principalmente pelo papel que representa na transmissão de vírus da raiva ${ }^{8}$.

Os morcegos atuam como hospedeiros de bactérias, fungos, protozoários e vírus e também podem atuar como vetores mecânicos de Trypanosoma evansi. Diferentes espécies de flagelados tripanosomatídeos são descritas nesses animais, sobretudo do gênero Trypanosoma ${ }^{13671013}$. Nas Américas, sua importância aumenta devido à infecção natural por Trypanosoma cruzi, agente etiológico da doença de Chagas, muito embora seja desconhecido como esses animais atuam no ciclo desse protozoário em ambiente silvestre ${ }^{12}$.

No Estado do Rio de Janeiro, o estudo com morcegos vem sendo feito principalmente para o monitoramento desses animais no ciclo da raiva urbana, sendo tal trabalho realizado rotineiramente pelas Secretarias Estaduais de Saúde e Agricultura ${ }^{11}$, mediante captura de exemplares em diferentes locais do estado, para avaliação da presença de vírus e anticorpos específicos nesses animais.

Este trabalho objetivou avaliar por hemocultura a infecção natural por protozoários tripanosomatídeos em morcegos capturados em diferentes municípios do Estado do Rio de Janeiro, em associação ao Programa de manutenção de morcegos realizados por pesquisadores da Empresa de Pesquisa Agropecuária do Estado do Rio de Janeiro (PESAGRO-RIO).

1. Laboratório de Vigilância em Leishmanioses, Instituto de Pesquisa Clínica Evandro Chagas, Fundação Oswaldo Cruz, Rio de Janeiro, RJ. 2. Laboratório de Biologia Animal, Empresa de Pesquisa Agropecuária do Estado do Rio de Janeiro, Niterói, RJ.

Apoio financeiro: Fundação de Apoio a Pesquisa do Estado do Rio de Janeiro (FAPERJ)

Endereço para correspondência: Dra. Juliana Helena da Silva Barros. Laboratório de Vigilância em Leishmaniose/ IPEC/FIOCRUZ. Av. Brasil 4365, Manguinhos, 21040-900 Rio de Janeiro, RJ.

Tel: 5521 3865-9541

e-mail: juliana.helena@ipec.fiocruz.br

Recebido para publicação em 02/05/2008

Aceito em 29/10/2008 
Os espécimes foram capturados em áreas urbanas, periurbanas e em locais pré-estabelecidos como próximo a currais, forros de casas, manilhas de água, cavernas ou abrigos naturais de morcegos, empregando redes de neblina (mist-nets), puçá e luvas de raspa de couro. Após a captura os animais eram imediatamente anestesiados utilizando uma combinação de 1/1 de xilocaína e ketamina $(0,1 \mathrm{mg} / 100 \mathrm{~g}$ peso corporal), por via intramuscular na pata posterior esquerda. Para a coleta de sangue o animal era colocado em decúbito dorsal sobre uma superfície rígida com as asas abertas para a realização da punção cardíaca, utilizando seringa de $1 \mathrm{~mL}$ acoplada a agulha $25 \times 7 \mathrm{~mm}$ para Desmodus rotundus e espécies maiores, e seringa de tuberculina com agulha intradérmica para as espécies menores. De acordo com a massa corporal, foi coletado até $1 \mathrm{~mL}$ de sangue. Após este procedimento 0 animal foi identificado com colar e liberado no mesmo local da captura.

O sangue coletado foi enviado ao Laboratório de Vigilância em Leishmanioses/Instituto de Pesquisa Clínica Evandro Chagas/ Fundação Oswaldo Cruz (IPEC/FIOCRUZ) sob refrigeração $\left(+/-4^{\circ} \mathrm{C}\right)$, no prazo máximo de 24 horas. Após ser submetido à centrifugação durante 20 minutos a $3.500 \mathrm{rpm}$ a $4^{\circ} \mathrm{C}$, o sedimento de hemácias foi ressuspenso em cerca de $6 \mathrm{~mL}$ de meio de cultura Schneider's suplementado com 10\% de soro fetal bovino (SFB) e antibióticos (penicilina e estreptomicina). A suspensão foi homogeneizada e distribuída para 4 tubos contendo meio sólido NNN (Novy, Nicolle e MacNeal). Os tubos semeados foram acondicionados em estufa biológica à temperatura de $28^{\circ} \mathrm{C}$ e examinados, por microscopia ótica, coletando-se amostras da fase líquida do meio e depositadas entre lâmina e lamínula para pesquisa de formas flageladas. Os exames foram realizados semanalmente durante dois meses, sendo que com 30 dias foi adicionado em cada tubo de cultura cerca de $1 \mathrm{~mL}$ de meio de cultura Schneider com $10 \%$ de SFB.

No período de agosto de 2004 a fevereiro de 2007, foram examinados 86 morcegos, capturados nos Municípios de São Gonçalo, Miracema, Niterói, Maricá, Paraty, Itaperuna e Rio de Janeiro. Dos exemplares avaliados, 78 possuíam hábitos alimentares hematófagos, sendo 77 da espécie Desmodus rotundus e um da espécie Diaemus youngii; 4 possuíam hábitos frugívoros: 2 da espécie Artibeus cinereus, um da espécie Carollia perspicillata e outro da espécie Glossophaga sorcina e 3 exemplares de espécie de hábitos insetívoros (Lonchorbina aurita).

Das 86 hemoculturas realizadas, foi possível o isolamento de flagelados tripanosomatídeos em 21 exemplares hematófagos ( $\left.n^{0} 78 ; 26,5 \%\right)$ e de um exemplar insetívoro $\left(n^{0} 3 ; 33,3 \%\right)$ (Tabela 1). Vinte e uma hemoculturas foram perdidas por contaminantes e as demais apresentaram resultados negativos. Das 22 (25,6\%) amostras de protozoários flagelados isolados, 5 não evoluíram nos meios de cultura utilizados e as demais estão sendo mantidas por passagens semanais no mesmo meio de cultura descrito acima, apresentando intenso polimorfismo entre os isolados (Figura 1).

A investigação de parasitas hemoflagelados, em animais silvestres e domésticos, tem sido foco de estudo em diferentes
Tabela 1 - Resultado da avaliação, por bemocultura, de morcegos capturados em diferentes municípios do Estado do Rio de Janeiro.

\begin{tabular}{|c|c|c|c|}
\hline \multirow[b]{2}{*}{ Município } & \multirow[b]{2}{*}{ Espécie } & \multicolumn{2}{|c|}{ Hemocultura } \\
\hline & & $\begin{array}{c}\text { exemplares } \\
\text { examinados }\left(\mathrm{n}^{0}\right)\end{array}$ & $\begin{array}{c}\text { amostras } \\
\text { positivas }\left(n^{\circ}\right)\end{array}$ \\
\hline São Gonçalo & Desmodus rotundus* & 12 & 3 \\
\hline Niterói & Desmodus rotundus* & 6 & 5 \\
\hline Maricá & Desmodus rotundus* & 3 & 3 \\
\hline Itaperuna & Desmodus rotundus* & 2 & 0 \\
\hline Rio de Janeiro & Desmodus rotundus* & 17 & 0 \\
\hline \multirow[t]{4}{*}{ Miracema } & Desmodus rotundus* & 37 & 9 \\
\hline & Diaemus youngi $i^{*}$ & 1 & 0 \\
\hline & Lonchorhina aurita** & 3 & 1 \\
\hline & Artibeus cinereus ${ }^{* * * *}$ & 1 & 0 \\
\hline \multirow[t]{4}{*}{ Paraty } & Desmodus rotundus* & 1 & 1 \\
\hline & Glossophaga sorcina*** & 1 & 0 \\
\hline & Artibeus cinerus $^{* * * *}$ & 1 & 0 \\
\hline & Carollia perspicillata ${ }^{* * * *}$ & 1 & 0 \\
\hline Total & & 86 & 22 \\
\hline
\end{tabular}

*hematófago, **insetívoro, ***frugívoro.

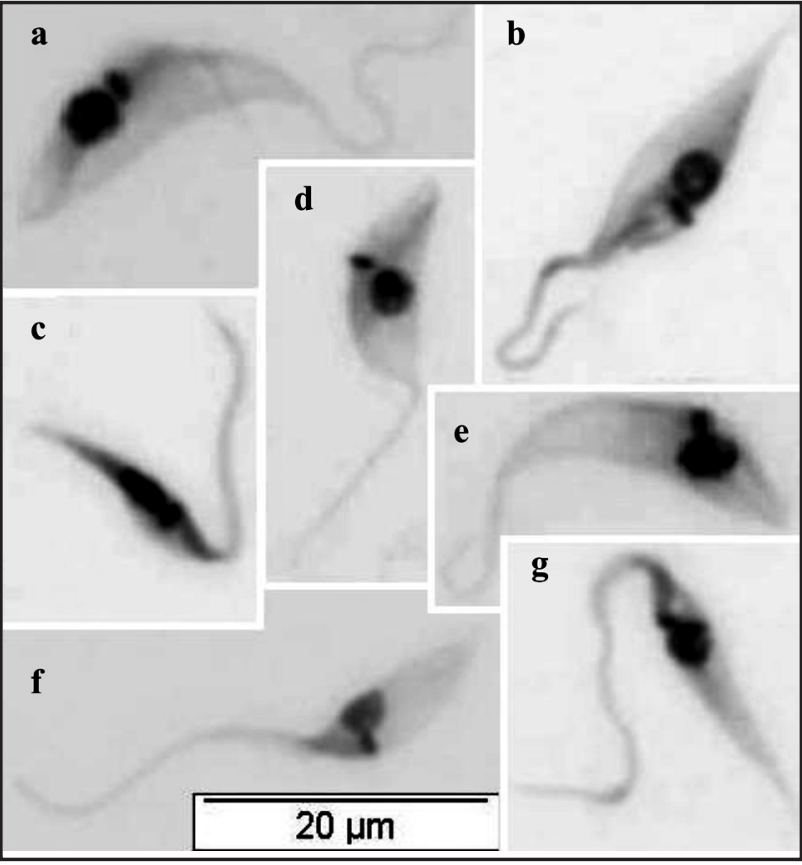

Figura 1 - Fotomicrografia de flagelados tripanosomatideos isolados de morcegos capturados no município de Miracema: isolado R.1011 (a, d, e); isolado R.1013 (b, f, g); isolado R.069 (c). Coloração pelo Giemsa (x 1000).

áreas geográficas. Nesse contexto, os morcegos vêm recebendo atenção já que atuam como reservatórios e transmissores de agentes de importância em Saúde Pública ${ }^{4}$. Este estudo demonstrou a infecção natural de morcegos por flagelados tripanosomatídeos em cinco Municípios do Estado do Rio de Janeiro.

A hemocultura embora altamente específica para protozoários sanguíneos, possui sensibilidade relativa, diretamente associada às condições de cultivo e ao volume de sangue semeado ${ }^{2}$. Em todos os animais, não foi possível a coleta de volumes maiores que $1 \mathrm{~mL}$, o que pode ter sido um fator de influência para o sucesso de isolamento. 
Com o crescimento das populações, muitas vezes ocorrendo de forma desordenada, mamíferos, como os morcegos, vêm encontrando espaço de desenvolvimento em áreas urbanas. Tais fatos favorecem a urbanização de agentes patogênicos ao homem ${ }^{14}$, como o vírus da raiva e possivelmente tripanosomatídeos, demonstrando a importância de estudos envolvendo a infecção natural desses animais.

Embora pouco se saiba sobre o papel que os morcegos assumem no ciclo epidemiológico de certas espécies de tripanosomas, o fato de albergarem parasitas como Trypanosoma cruzi ${ }^{5}$, Trypanosoma evansi e Trypanosoma equiperdum ${ }^{10}$ constitui elemento de grande preocupação para a saúde humana e animal. Por essa razão, Desmodus rotundus foi a espécie mais investigada neste estudo, uma vez que morcegos de hábitos hematófagos podem no ato de hematofagia adquirir e veicular agentes patogênicos, como é descrito no ciclo da raiva em ambiente rural ${ }^{11}$.

No Estado do Rio de Janeiro, são poucos os relatos da infecção natural de morcegos por flagelados tripanosomatídeos e o encontro de 22 amostras demonstra claramente o envolvimento desses animais com esses protozoários. Tal achado torna-se relevante, já que muitas espécies de morcegos adaptam-se aos ambientes modificados e instalam-se em áreas domiciliares, representando um risco potencial para a disseminação no ambiente doméstico e peridoméstico. Deve-se levar em conta, também, que as colônias de morcegos eventualmente trocam de abrigo, aumentando assim a possível dispersão de algumas espécies de tripanosomatídeos que, por sua vez, podem ser agentes/vetores de importantes doenças. Os isolados obtidos estão sendo estudados para identificação etiológica.

Os resultados deste estudo podem contribuir para o conhecimento e mapeamento das espécies de tripanosomatídeos que estejam circulando entre morcegos no Estado do Rio de Janeiro.

\section{AGRADECIMENTOS}

Aos técnicos da Equipe de Vigilância Hospedeiros, Reservatórios e Animais Peçonhentos da Secretaria Estadual de Saúde e Defesa Civil do Rio de Janeiro (SESDEC-RJ), pela adesão e participação no trabalho de campo.

\section{REFERÊNCIAS}

1. Bower SM, Woo PTK. Two new species of trypanosomes (subgenus Schizotrypanum) in bats from southern Ontário. Canadian Journal of Zoology 59: 530-545, 1981 .

2. Chiari E, Dias JCP, Lana M, Chiari CA. Hemoculture for the parasitological diagnosis of human chronic Chagas disease. Revista do Instituto de Medicina Tropical de São Paulo 22:19-23, 1989.

3. Deane L. Tripanosomatídeos de mamíferos da Região Amazônica I. Alguns flagelados encontrados no sangue de mamíferos silvestres do estado do Pará. Revista do Instituto de Medicina Tropical de São Paulo 3:15, 1961.

4. Field H, Mackenzie J, Daszak P. Novel viral encephalitides associated with bats (Chiroptera) - host management strategies. Archives of Virology 18(suppl):113-121, 2004.

5. Funayama GK, Barreto MP. Estudos sobre reservatórios e vetores silvestres do Trypanosoma cruzi. XXXVIII: Infecção natural do morcego Desmodus rotundus rotundus (Geofroy, 1810) pelo T. cruzi. Revista Brasileira de Biologia 30:13-19, 1970.

6. Hoare CA. The Trypanosomes of Mammals: A zoological monograph. Blackweel Scientific Publications, Oxford and Edinburg, UK, p. 327-400, 1972.

7. Marinkelle CJ. The biology of the trypanosomes of bats. In: Lumdsen WHR, Evans DA (eds) Biology of the Kinetoplastida. Academic Press New York, p.175-216, 1976.

8. Mayen F. Haematophagus bats in Brazil, their role in rabies transmission, impact on public health, livestock industry and alternatives to an indiscriminate reduction of bat population. Journal of Veterinary Medicine, Series B, Infectious Diseases and Veterinary Public Health 50:469-472, 2003

9. Messenger SL, Rupprecht CE, Smith SJ. Chapter 14 - Bats, emerging virus infections and the rabies paradigm. In: Kunz TH, Fenton MB (eds) Bat Ecology. The University of Chicago Press, Chicago, p.622-679, 2003.

10. Molyneux DH. Trypanosomes of bats. In: Kreier JP, Baker JR (eds) Parasitic protozoa. Academic Press, San Diego, p. 195-224, 1991.

11. Romijn PC, Van Der Poel WHM, Van Der Heide R, Cattaneo CAM, Silva RCF. Study of Lyssaviruses of bat origin as a source of rabies for other animal species in the State of Rio de Janeiro - Brazil. The American Journal of Tropical Medicine and Hygiene 69:81-86, 2003.

12. Saravia NG, Holguín AF, Cibulskis RE, D’Alessandro A. Divergent isoenzyme profiles of sylvatic and domiciliary Trypanosoma cruz $i$ in the eastern plains, piedmont, and highlands of Colômbia. The American Journal of Tropical Medicine and Hygiene 36: 59-69, 1987.

13. Steindel M, Grisard EC, Pinto CJC, Cordeiro FD, Ribeiro-Rodrigues R, Romanha AJ. Characterization of trypanosomes from the subgenus Schizotrypanum isolated from bats, Eptesicus sp. (Chiroptera:Vespertilionidae), captured in Florianópolis, Santa Catarina, Brazil. Journal of Parasitology 84:601-607, 1998.

14. Taylor LH, Latham SM, Wollhouse MEJ. Risk factors for human disease emergente Philosophical Transactions of the Royal Society London B 356:983-989, 2001. 